Intractable childhood epilepsy: Early identification

Berg et al. (p. 1445)

prospectively followed 600

children in child neurology

practices for factors that predicted intractability, defined

as at least one seizure/month for 18 months despite two drugs.

The $10 \%$ who were intractable were those with higher seizure frequency and with focal slowing on the initial EEG, and who had neonatal or acute symptomatic status epilepticus. $\$$ The accompanying editorial by Holmes and Engel (p. 1430) critiques the criteria for intractability, noting that some patients achieve control after 18 months and that some initially controlled patients later became intractable. Still, these criteria pave the way for trials of earlier, more aggressive interventions in uncontrolled epilepsy: surgery, new medications, and diet.

\section{Carpal tunnel syndrome (CTS)}

Three papers and an editorial consider CTS. Padua et al. and the Italian CTS Study Group (p. 1459) observed the natural history of 274 hands with CTS, documenting both clinical and EMG improvement in many. Younger patients and those with recent severe symptoms were more likely to improve. The Wong et al. (p. 1565) controlled trial of oral vs injected prednisolone in CTS showed that injection was more effective. Stevens et al. (p. 1568) studied 258 computer users. Thirty percent had sensory symptoms suggesting CTS but only $3 \%$ had clinical and EMG evidence of CTS. Olney's editorial ( $p$. 1431) focuses on the remaining challenges in understanding the cause and improving the treatment of CTS. He points out that not only do the hand symptoms of computer keyboard users rarely prove to be from CTS, but "ergonomic" measures have not been proven to prevent CTS. He points out that these papers add data that will need to be incorporated into the next AAN practice parameter on CTS.

\section{Mosaicism in NF1 and NF2 \\ Ruggieri and Huson (p. 1433) review the clinical picture that somatic mosaicism commonly produces in neurofibromatosis. Their illustrations of segmental and unilateral lesions show beautifully the mosaicism frequent in NF: focal neuropathy, dermatomal neurofibromatosis, hemilateral dermatoma, and hyper- pigmentation. Many other autosomal dominant disorders can have such mosaicism.}

\section{Clinical trials in MS}

Does IFNß-1a prevent progression and disability in MS? Hughes et al. (p. 1496) and $\mathrm{Li}$ et al. (p. 1505) for the SPECTRIMS study group report clinical and MRI results of a controlled trial of IFNß-1a in secondary progressive MS. The 3-year parallel group study randomized 618 patients into placebo vs high-dose vs low-dose IFNß-1a groups. They found no benefit to progression of disability but confirmed the reduction in relapses seen in earlier IFN trials. Semiannual MRI data (617 patients) showed marked reduction in active lesions with both doses and fewer accumulated lesions with both doses. The greatest benefit was detected in patients with frequent relapses before treatment. Patients with neutralizing IFN antibodies did not benefit. $\downarrow$ In another trial that addressed the permanent visual loss of patients with MS, Noseworthy et al. (p. 1514) report that IVIg did not improve the persistent visual loss in patients with MS.

\section{Botox for essential tremor (ET)?}

Brin et al. (p. 1523) in a parallel group trial compared placebo vs low-dose vs high-dose Botox injected into wrist flexors and extensors in 133 patients with ET. At 4- and 16-week follow-up, postural tremor was improved but neither hand function nor kinetic hand tremor improved. Botox caused hand weakness at both doses.

\section{Early identification of dementia: Memory decline vs memory impairment Collie et al. (p. 1533) propose that memory decline rather than an absolute measure of memory loss would be most indicative of incipient dementia. They studied word list delayed recall five times over 2 years in 101 healthy subjects (mean age 62). They found that the one third of healthy subjects whose memory declined met criteria for early dementia, whereas only $5 \%$ of those who did not decline over the 2 years met such criteria.}

\footnotetext{
Abciximab for thrombolysis Houdart et al. (p. 1582) report lysis of established thrombosis extracranial vessels in three patients. Lee et al. (p. 1585) report successful lysis of an occluded middle cerebral artery-refractory to both IV and intra-arterial thrombolysis and to balloon angioplasty.
} 


\title{
Neurology
}

\author{
June 12 Highlights \\ Neurology 2001;56;1429 \\ DOI 10.1212/WNL.56.11.1429
}

This information is current as of June 12, 2001

\section{Updated Information \&} Services

Permissions \& Licensing

Reprints including high resolution figures, can be found at: http://n.neurology.org/content/56/11/1429.full

Information about reproducing this article in parts (figures,tables) or in its entirety can be found online at:

http://www.neurology.org/about/about_the_journal\#permissions

Information about ordering reprints can be found online:

http://n.neurology.org/subscribers/advertise

Neurology ${ }^{\circledR}$ is the official journal of the American Academy of Neurology. Published continuously since 1951, it is now a weekly with 48 issues per year. Copyright . All rights reserved. Print ISSN: 0028-3878. Online ISSN: 1526-632X.

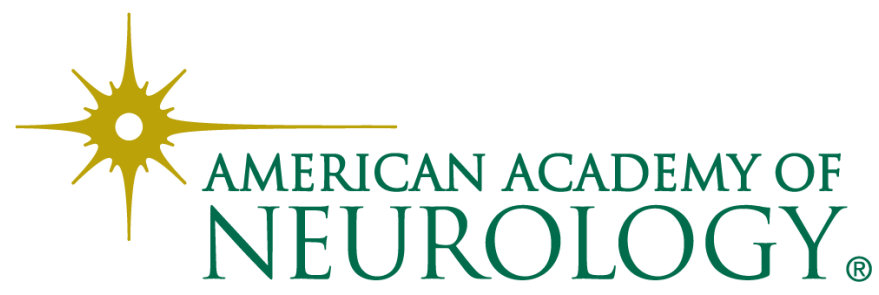

